ARTICLE

https://doi.org/10.1038/s41467-021-24678-5

\title{
Simultaneous construction of axial and planar chirality by gold/TY-Phos-catalyzed asymmetric hydroarylation
}

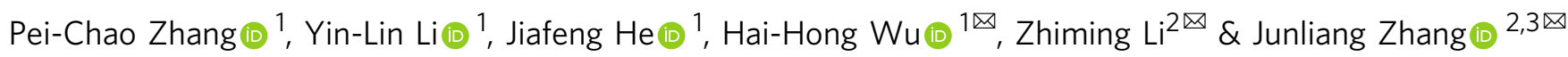

The simultaneous construction of two different chiralities via a simple operation poses considerable challenge. Herein a cationic gold-catalyzed asymmetric hydroarylation of orthoalkynylaryl ferrocenes derivatives is developed, which enable the simultaneous construction of axial and planar chirality. The here identified TY-Phos derived gold complex is responsible for the high yield, good diastereoselectivity (>20:1 dr), high enantioselectivities (up to $99 \%$ ee) and mild conditions. The catalyst system also shows potential application in the synthesis of chiral biaryl compounds. The cause of high enantioselectivity of this hydroarylation is investigated with density functional theory caculation.

\footnotetext{
${ }^{1}$ Shanghai Key Laboratory of Green Chemistry and Chemical Processes, School of Chemistry and Molecular Engineering, East China Normal University, Shanghai, China. ${ }^{2}$ Department of Chemistry, Fudan University, Shanghai, China. ${ }^{3}$ State Key Laboratory of Organometallic Chemistry, Shanghai Institute of Organic Chemistry, CAS, Shanghai, China. ${ }^{凶}$ email: hhwu@chem.ecnu.edu.cn; lizm@fudan.edu.cn; junliangzhang@fudan.edu.cn
} 
A $s$ an effective and exceptionally versatile strategy, the development of catalytic asymmetric intramolecular hydroarylation for the construction of axial ${ }^{1-10}$ and planar $^{11-13}$ chirality or helicenes ${ }^{14-20}$ has received much attention $^{21-32}$. Various transition metal catalysis involving $\mathrm{Au}, \mathrm{Pt}$, $\mathrm{Rh}$, and $\mathrm{Pd}$, have been reported in this regard. For instance, the groups of Alcarazo ${ }^{1,14,16,18}$ and Tanaka ${ }^{6,15,17}$ extensively studied the Au-catalyzed and Rh-catalyzed intramolecular alkyne hydroarylation to achieve enantioselective synthesis of axially chiral biaryls and helicenes, respectively (Fig. 1a). In 2013, Uemura et al. ${ }^{10}$ developed a Pd-catalyzed asymmetric cycloisomerization of enynes for the construction of axially chiral biaryl. The group of Urbano and Carreño ${ }^{11}$ developed an Aucatalyzed cyclization to construct the planar naphthalene-fused ferrocenes in 2016 (Fig. 1a). Later, Shibata et al. ${ }^{12}$ reported the similar reaction enabled by a Pt-catalysis. Meanwhile, the capacity of intramolecular hydroarylation is impressively complemented by various other versatile stereocontrolled methodologies. For example, Shibata ${ }^{2}$ and co-workers reported a Rh-catalysed enantioselective synthesis of axially chiral PAHs via regioselective cleavage of biphenylenes. Stará and Starý19,20 developed a $\mathrm{Ni}$-catalysed enantioselective $[2+2+2]$ cycloisomerisation of aromatic triynes to obtain the helicene derivatives. Toullec ${ }^{3}$, $\mathrm{Yan}^{4}$, Irie ${ }^{5}$, and Sparr $^{7-9}$ independently demonstrated efficient organocatalytic enantioselective cyclization of aryl-alkynes to construct valuable molecules containing axial or axial and helical stereogenic elements.

In this work, the simultaneous construction of axial and planar chiralities is realized via the gold-catalyzed ${ }^{33-42}$ asymmetric intramolecular hydroarylation of readily available oalkynylferrocene derivatives $1^{43}$ (Fig. 1c). And the simultaneous construction of two different types of chiralities is now flourishing development (Fig. 1b) ${ }^{44-51}$.

\section{Results}

Optimization of the reaction conditions. However, to the best of our knowledge, simultaneous construction of multiple chiralities by asymmetric gold catalysis has not been reported so far, this hypothesis faced considerable challenges: (1) the universal and efficient asymmetric intramolecular desymmetric cyclization for the construction of planar ferrocene derivatives was not well developed (In the work of refs. 11,12, 10-20 mol\% catalytic loading was used), (2) on the other hand, simultaneous construction of axial and planar chiral molecules via asymmetric catalysis has rarely been reported ${ }^{52,53}$ and innate reluctance to undergo a related asymmetric desymmetric aromatization, and (3) the inherent difficulties to asymmetric gold catalysis, which stem from its linear coordination geometry and the outer-sphere nature of $\mathrm{Au}(\mathrm{I})$-catalysis ${ }^{44-50}$. To test our hypothesis, our investigation began with the cyclization of ortho-alkynylaryl ferrocene derivative 1aa. A series of commercially available chiral ligands were investigated (please find more details in the Supplementary Information (SI) Supplementary Fig. S3). Unfortunately, catalysts used by Urbano-Carreño ${ }^{11}$, Shibata ${ }^{12}$, or Uemura ${ }^{10}$ all failed to give the desired cyclization product (Fig. 2, entries 1-3). (R)DTBM-SEGPhos (L1), the commonly used chiral ligand in asymmetric gold catalysis, delivered the enantiomer of 2 aa in $15 \%$ NMR yield with $80 \%$ ee and 3:1 diastereoselectivity. (S,S)-Ph-BPE (L2) could give the product 2 aa in quite low enantioselectivity and conversion. (R)-BINAP (L3) furnished 2aa in $62 \% \mathrm{NMR}$ yield with $51 \%$ ee and 5:1 d.r., and the dominant Brønsted acid $(R)$-CPA (L4) in the field of atroposelective synthesis of axially chiral molecules, cylohexanediamine-derived $(S, S)$-DACH-Phenyl Trost Ligand (L5), (R)-BI-DIME (L6), Binol-derived phosphor-amidite $(\mathrm{S} a, R, R)$-CPPA (L7), chiral oxazoline-phosphine ligand $(R)$-tBu-PHOX (L8), all have insufficient catalytic activity. We next turned to investigate our developed chiral sulfinamide phosphine (Sadphos), which has shown good performance in asymmetric gold catalysis ${ }^{41-43}$ (Sadphos are commercially available (Daicel and Strem), which are also easily prepared in 2-4 steps from chiral tert-butane sulfinamide.) (Fig. 2). The gold complexes derived from Ming-Phos ${ }^{42,43,54-56}$, Xu-Phos ${ }^{57-61}$, Xiang-Phos ${ }^{62-65}$, PC-Phos ${ }^{41,66-68}$ and TY-Phos ${ }^{69}$ could deliver (-)-2aa in up to $83 \%$ yield with $85 \%$ ee. We found that enantioselectivity roughly correlates to the electrical properties of the Sadphos, with a more $\sigma$-donating ligand providing a higher enantioselectivity and catalytic activity. Notably, Au(TY-Phos)Cl could be easily synthesized in a gram scale via a five-steps in "one-pot" synthesis (for more details, see the SI). Inspired by this promising result, we varied the Ar group of TY-Phos (TY2-TY4) and introduced electron-donating groups to the aryl moiety of TY-Phos, structured as TY5-TY6 with alkyl groups. Gratifyingly, the product 2 aa could be obtained in $83 \%$ yield with $85 \%$ ee and 5:1 d.r. with the use of $[\mathrm{Au}(\mathrm{TY} 5)] \mathrm{BAr}^{\mathrm{F}}$ as the catalyst. Moreover, $\mathrm{N}-\mathrm{Me}$-TY5 delivered much lower enantioselectivity to $46 \%$ ee (Fig. 2, entry 10). Then, the effect of the counterion was investigated (Fig. 2, entries 8, 11-13) ${ }^{70}$, among which sodium tetrakis [3,5-bis(trifluoro-methyl) phenyl]borate $\left(\mathrm{BAr}^{\mathrm{F}-}\right)$ delivered the best enantioselectivity and reactivity. Subsequently, either lowering the temperature to $-10^{\circ} \mathrm{C}$ or using other solvents such as DCE and toluene failed to give better result (Fig. 2, entries 14-16).

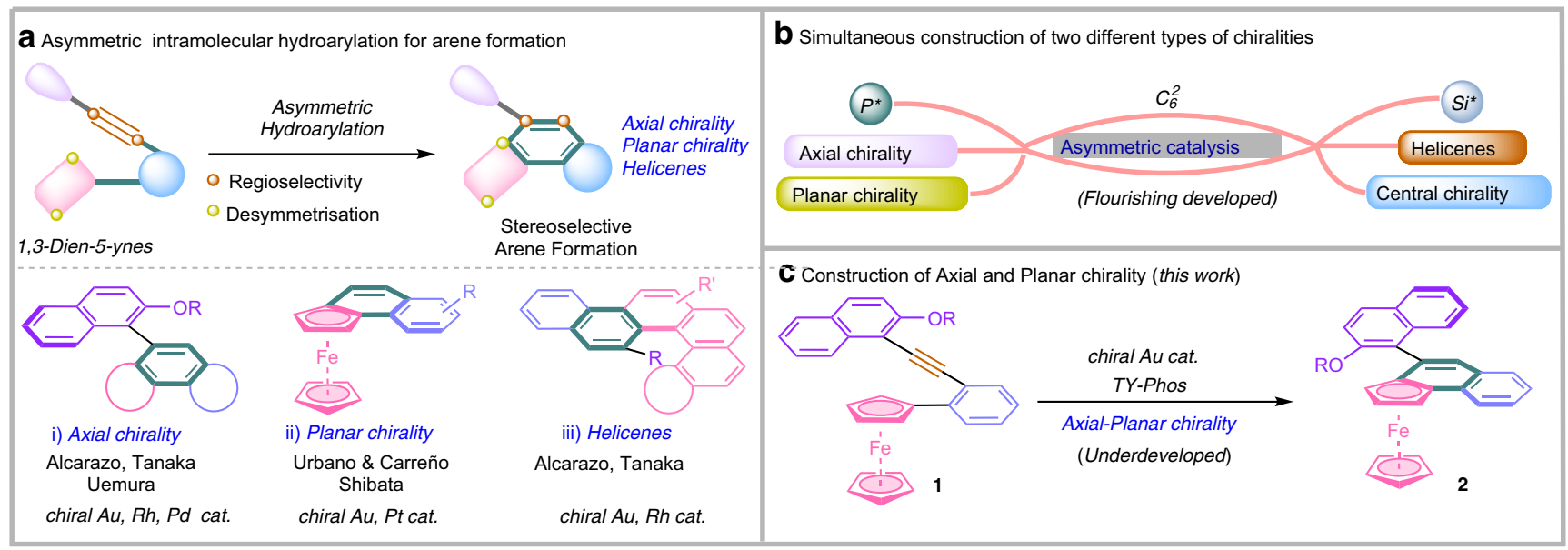

Fig. 1 Background and project synopsis. a Asymmetric intramolecular hydroarylation for arene formation. b Simultaneous construction of two different types of chiralities. c Construction of Axial and Planar chirality (this work). 


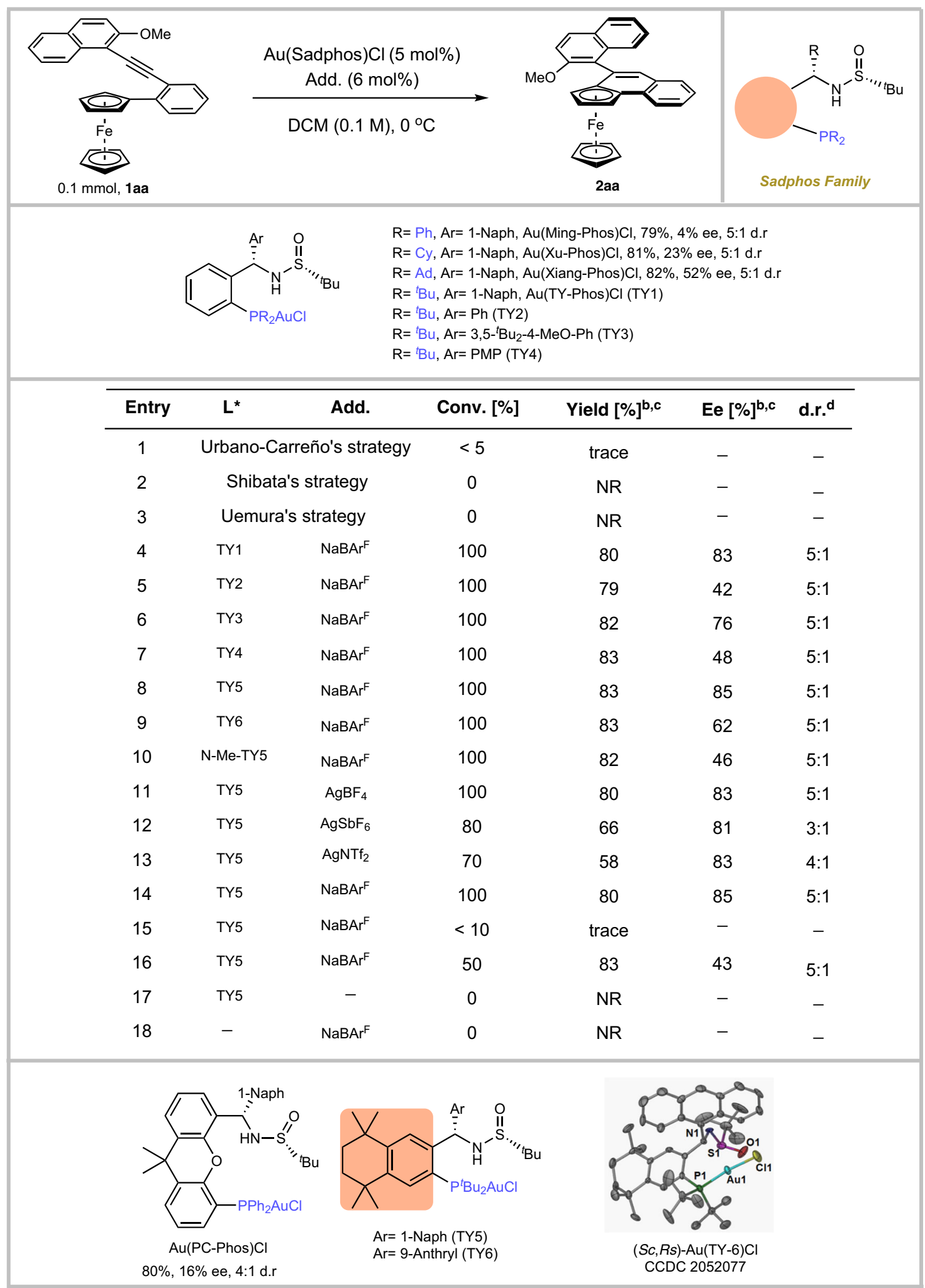

Fig. 2 Optimization of reaction conditions. a Unless otherwise noted, all reactions were carried out with $0.1 \mathrm{mmol}$ of $\mathbf{1 a a}$ and $10 \mathrm{~mol} \%$ of catalyst (Au: $\mathrm{P}$ : $\mathrm{NaBArF}$ (additive) $=1: 1: 1.2)$ in $1.0 \mathrm{~mL} \mathrm{DCM}$ at $0{ }^{\circ} \mathrm{C}$ for $24 \mathrm{~h}$; ${ }^{b}$ ssolated yield. ${ }^{C}$ Determined by chiral HPLC. ${ }^{d}$ Determined by NMR. ${ }^{e} \mathrm{At}-10{ }^{\circ} \mathrm{C}$; $f_{\mathrm{In}} 1.0 \mathrm{~mL}$ toluene; 9 In $1.0 \mathrm{~mL}$ DCE. Shibata's strategy: $\mathrm{PtCl}_{2}$ (cod) (10 mol\%), (S,S)-Ph-BPE (10 mol\%) and AgBF 4 (20 mol\%) in DCE at r.t.; Urbano-Carreño's strategy: $(R)$-DTBM-SEGPhos $(\mathrm{AuCl})_{2}(10 \mathrm{~mol} \%)$ and $\mathrm{AgSbF}_{6}(20 \mathrm{~mol} \%)$ in toluene at $0^{\circ} \mathrm{C}$; Uemura's strategy: $\left[\mathrm{Pd}(\mathrm{MeCN})_{4}\right]\left(\mathrm{BF}_{4}\right)_{2}(5 \mathrm{~mol} \%)$ and $(R)$ Binap (10 mol\%) in DCE at $60^{\circ} \mathrm{C}$. 


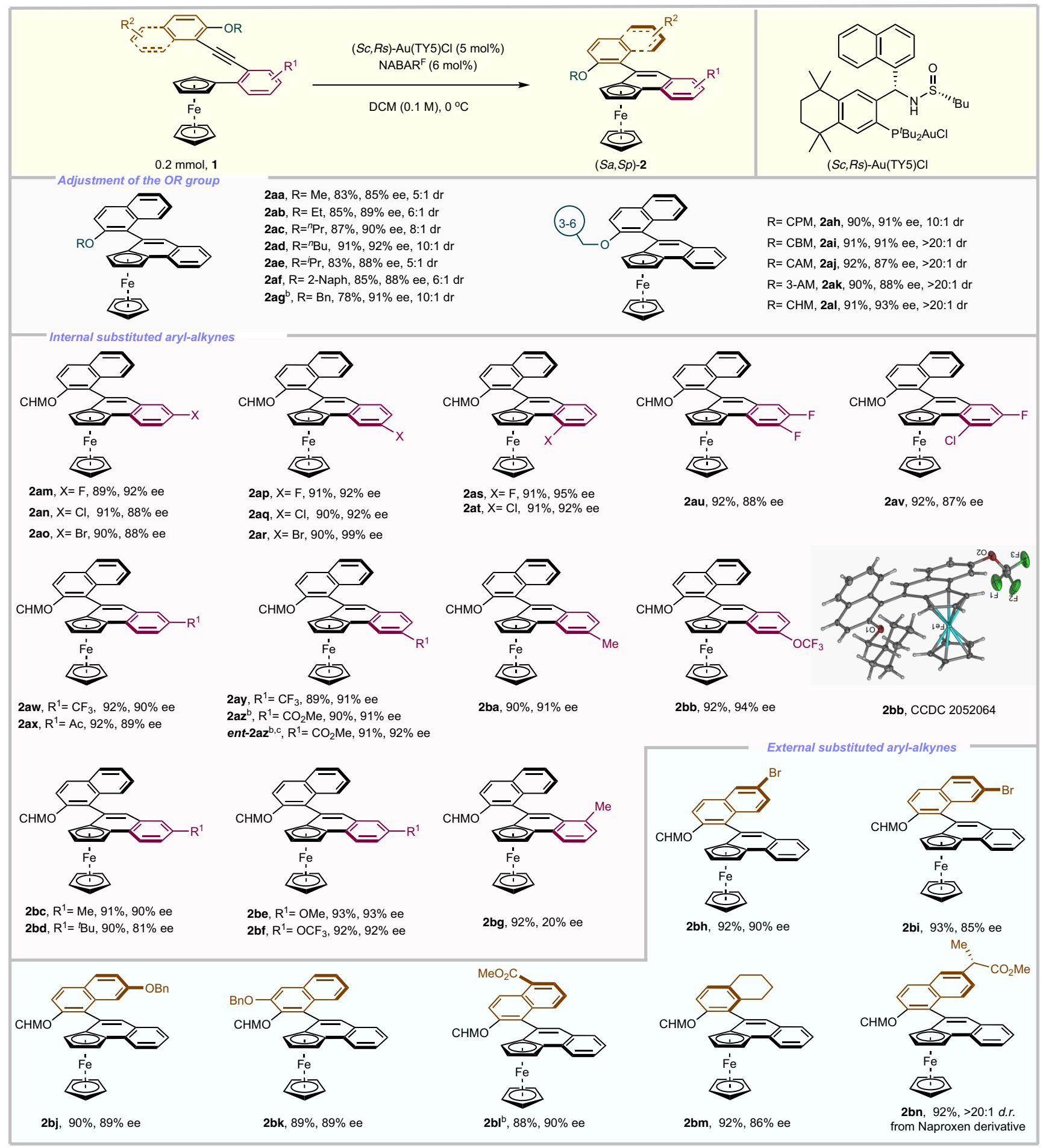

Fig. 3 Exploration of substrate scopea. ${ }^{a}$ Reaction conditions: unless otherwise noted, all reactions were carried out with $0.2 \mathrm{mmol}$ of $\mathbf{1}, \mathrm{Au}(\mathrm{TY} 5) \mathrm{Cl}(5 \mathrm{~mol}$ \%), $\mathrm{NaBAr} F(6 \mathrm{~mol} \%)$ in $2.0 \mathrm{~mL} \mathrm{DCM}$ at $0{ }^{\circ} \mathrm{C}$; isolated yields; the ee values were determined by chiral $\mathrm{HPLC},>20: 1 \mathrm{dr} .{ }^{b} \mathrm{Au}(\mathrm{TY} 5) \mathrm{Cl}(10 \mathrm{~mol} \%), \mathrm{NaBAr} F(12$

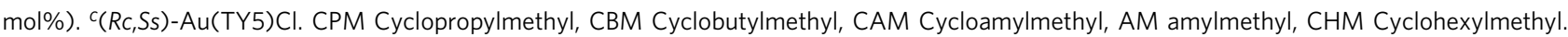

Finally, no counterion or only additives which all have not catalytic activity (Fig. 2, entry 18-19).

Reaction scope study. Further optimization focused on adjustment of the OR group. Surprisingly, a meaningful increasing enantioselectivity and reactivity and diastereoselectivity occurred when the $\mathrm{R}$ was switched to the longer carbon chains (Fig. 3, 2aa2ad). Bulkier groups ( $\left.\mathrm{O}^{i} \mathrm{Pr}, \mathrm{O}-2-\mathrm{Naph}\right)$ could furnish the corresponding products in $88 \%$ ee (2ae, 2af). Better enantioselectivity (92\% ee) was achieved with a benzyl $(\mathrm{Bn})$ protecting group (2ag), however, the diastereoselectivity and reactivity is still far from ideal. The cyclohexylmethyl (CHM) group seems to be crucial to deliver good result (2ah-2al). A series of internal substituted aryl-alkynes were then prepared and tested to this cyclization process. A good tolerance towards halogens (1am-1av), electron-withdrawing substituents (1aw-1az), electron-withdrawing substituents (1aw-1az), electron-donating 


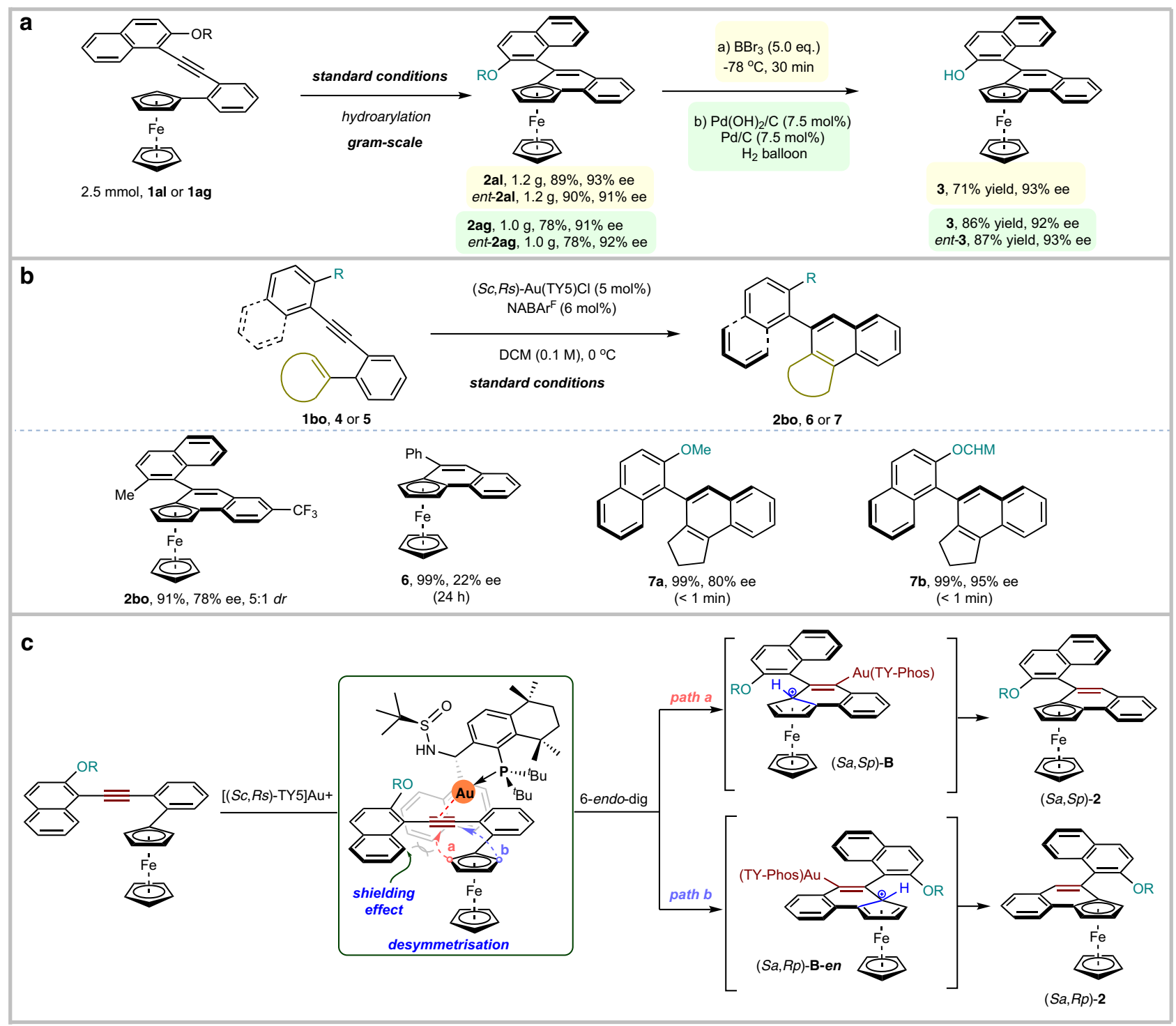

Fig. 4 Proof-of-principle study. a The practical utility. b mechanism study. c proposed asymmetric induction model.

substituents and steric hindrance groups (1ba-1bf) on different positions of the phenyl ring $\left(\mathrm{R}^{1}\right)$ were observed and the corresponding products (2am-2bf) were obtained in $88-92 \%$ yields with $81-99 \%$ ee. The structure and configuration of $(S a, S p)$-2bb was unambiguously determined via its $\mathrm{X}$-ray analysis. There is an obvious substituent effect at the ortho-position of the aryl alkyne, indicating that the steric hindrance at ortho-position is unbeneficial to the enantioselectivity (2bg). Gratifyingly, the naphthyl and phenyl ring bearing electron-donating and electronwithdrawing groups at different positions $\left(\mathrm{R}^{2}\right)$, could deliver the desired products $(\mathbf{2} \mathbf{b h}-\mathbf{2} \mathbf{b m})$ in excellent yields with moderate to high ee. Then, employing the derivative of pharmaceutical naproxen as the substrate $\mathbf{1} \mathbf{b n}$, the corresponding product $\mathbf{2} \mathbf{b n}$ could be obtained in high yield with excellent diastereoselectivity.

To demonstrate the practical utility of this protocol for synthesis of ferrocene derivatives bearing axial and planar chirality (Fig. 4a), four reactions were carried out in gram scale under standard conditions. With the use of Au[TY5 $]^{+}$and its enantiomer, $1.2 \mathrm{~g}$ of 2al and ent-2al were produced in $89 \%$ yield with $93 \%$ ee and in $90 \%$ yield with $91 \%$ ee, respectively. $1.0 \mathrm{~g}$ of 2ag and ent-2ag were produced in $78 \%$ yield, $91 \%$ ee and $78 \%$ yield, $92 \%$ ee, respectively using the same procedure. Dealkylation of the aryl alkyl ethers 2al with concentrated boron tribromide led to chiral naphthol $\mathbf{3}^{71}$ in $71 \%$ yield $93 \%$ ee. Subsequent hydrogenation of aryl benzyl ethers $\mathbf{2 a g}$ and ent-2ag with the combination of $\mathrm{Pd}(\mathrm{OH})_{2}$ and $\mathrm{Pd} / \mathrm{C}$ in a $1: 1 \mathrm{ratio}^{72}$ afforded axial and planar chiral naphthol 3 in $86 \%$ yield $92 \%$ ee and ent-3 in $87 \%$ yield $93 \%$ ee, respectively.

To unravel the origin of the high enantioselectivity of the reaction (Fig. 4b), the asymmetric hydroarylations of 1-ethynyl-2methylnaphthalene derivative 1ao, 2-benzyne-1-ferrocenylbenzenes 4, 2-aryne-1-arylbenzenes $\mathbf{5 a}$ and $\mathbf{5 b}$ were also carried out under standard conditions. The $\mathbf{2 b o}$ could be obtained in $91 \%$ yield with $78 \%$ ee and 5:1 d.r., 6 with only the planar chirality was delivered in $99 \%$ yield but with low ee (22\% ee), in contrast, axial chiral $7 \mathbf{a}$ and $7 \mathbf{b}$ were obtained in $99 \%$ yield with $80 \%$ ee and $95 \%$ ee, respectively and the reactions were complete in less than one minute. Moreover, the linear relationship (see Supplementary Information (SI), Supplementary Fig. S2) between the ees of the $\mathrm{Au}(\mathrm{TY} 5) \mathrm{Cl}$ and those of product $\mathbf{2 a l}$ and the e.e. of the $\mathbf{2 a l}$ did not significantly change during the reaction, which reveal that the enantioselectivitydetermining step might involve a single chiral sulfinamide phosphine ligand and one gold species. In light of the structures of the chiral gold catalyst $\mathrm{Au}[(S c, R s)-\mathrm{TY} 5]^{+}$and the product 2 , a 


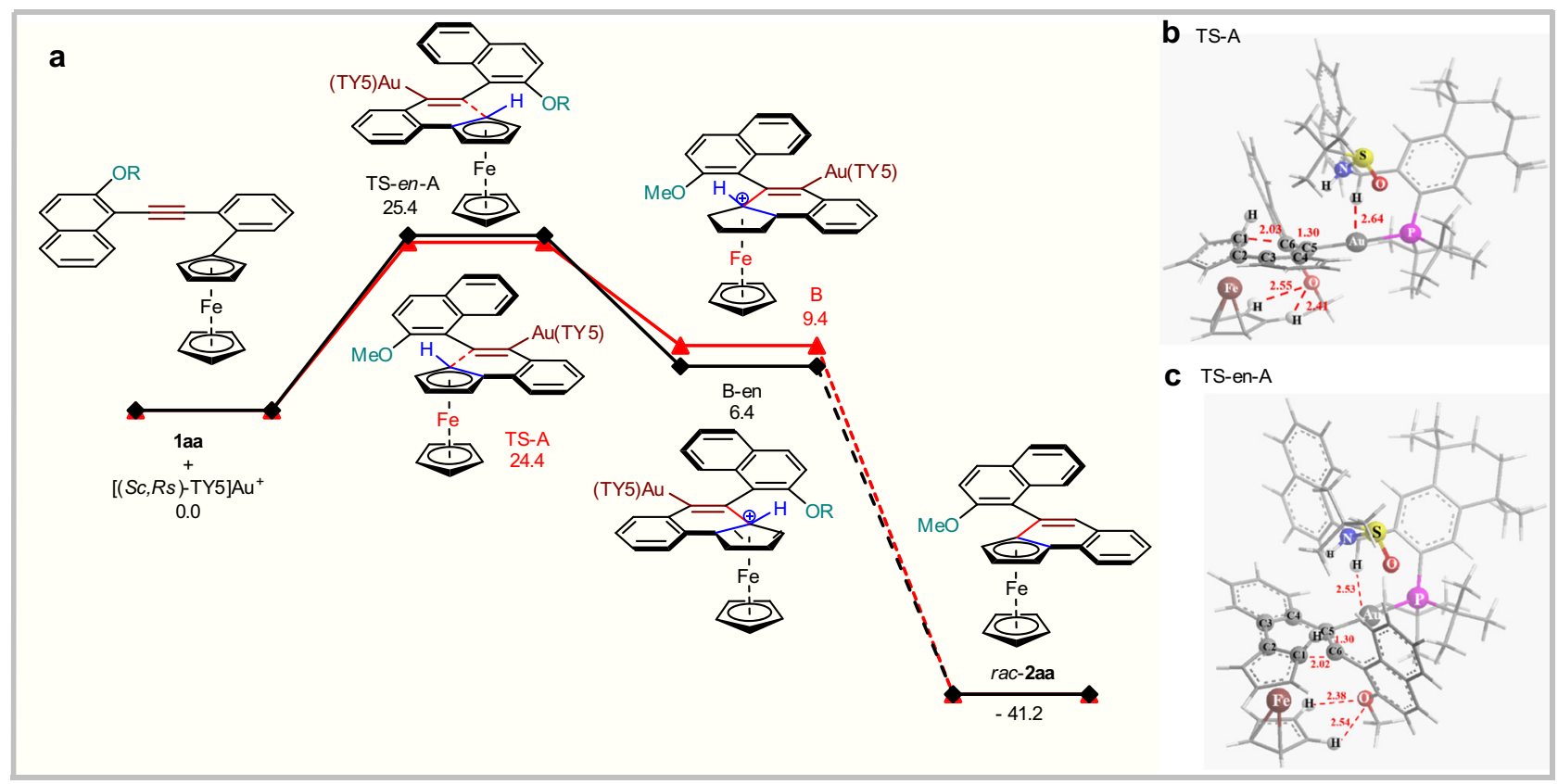

Fig. 5 Density functional theory (DFT) calculations. a The Free-energy reaction profiles $\left(\mathrm{kcal}_{\mathrm{mol}}^{-1}\right)$ for the reaction of 1aa, calculated with SMD Model (dichloromethane) using M062X at $273 \mathrm{~K} . \mathbf{b}$ and $\mathbf{c}$ The optimized transition states TS-A, TS-en-A for the enantioselectivity-determining step, calculated with SMD Model (Dichloromethane) with M062X method at $273 \mathrm{~K}$.

catalytic chirality-induction model was proposed for the reaction (Fig. 4c). The phosphine of the ligand and the alkyne coordinate to the $\mathrm{Au}(\mathrm{I})$ center. The Re face of alkyne and the alkoxyl group are shielded by the 1-naphthyl group of the ligand and the ferrocene group attack takes place at the $S i$ face to define the $(S p)$-planar chirality (path b), the alkoxyl group causes a blockage in the rotation of the naphthalene ring to define the $(\mathrm{Sa})$-axial chiralities. Because of these, it defines to form the product $(S a, S p)-2$ with excellent enantioselectivity and diastereoselectivity.

To shed light on the mechanism of the reaction, especially the planar enantioselectivity determining step catalyzed by $\mathrm{Au} /(\mathrm{Sc}$, $R s$ )-TY5, density functional theory (DFT) calculations were carried out with Gaussian 09 software package ${ }^{73-75}$. The geometry optimization and frequency calculations were carried out with M062X method and combined basis sets. That is, 6-31G (d) for the reactant 1aa fragment (except the hydrogen atom of the reaction site on the phenyl ring), the heteroatoms $\mathrm{P}, \mathrm{S}, \mathrm{N}, \mathrm{O}$ (connected with $\mathrm{S}$ atom) on the ligand $(S c, R s)$-TY5 and the carbon atoms linked with the above mentioned heteroatoms, $\mathrm{SDD}$ for $\mathrm{Au}$ and $\mathrm{Fe}$ atoms ${ }^{76}$. Considering the existence of hydrogen bonding, 6-31 $+\mathrm{G}(\mathrm{d}, \mathrm{p})$ basis set was applied for the $\mathrm{H}$ atom of the reaction site on the phenyl ring of laa and the $H$ atoms on the chiral carbon and on the $\mathrm{N}$ atom of $(S c, R s)$-TY5. 3-21 G basis set was used for all the other atoms. Truhlar and coworkers' SMD solvation model was employed to consider the solvent effect of dichloromethane $(\varepsilon=8.93)^{77}$. The geometry optimizations were performed without symmetry constraints and the nature of the extrema was checked by analytical frequency calculations. The intrinsic reaction coordinate calculation ${ }^{78,79}$ was also performed to verify the connectivity of the transition state and the energy minima. (see Supplementary Data for details)

The reaction of laa is selected as the model and we focused on the planar enantioselectivity of the reaction (Fig. 5). Enantiodetermining step of the reaction is the 6-endo-dig cyclization, that is, aromatic ferrocene attacks the alkyne moiety of 1aa, which is activated by cationic $\mathrm{Au} /(\mathrm{Sc}, R s)$-TY5. The following protodemetalation gives high enantioselective 2aa. Barriers (TS-A and TS-en-A) for the enantioselective step are 24.4 and $25.4 \mathrm{kcal} / \mathrm{mol}$ for the major and minor intermediates B and B-en, which means the reaction can proceed smoothly at reaction temperature. In addition, the difference of the two barriers are $1.0 \mathrm{kcal} / \mathrm{mol}$, that is also in good line with the experimental $85 \%$ ee value of 1aa reaction. Both TSs are late transition states, and the structures are closer to those of B and B-en (Fig. 5). For example, in both TSs, new 6-membered rings almost formed, C5-C6 distances are 1.30, very similar to that of normal double bonds. Meanwhile, weak interaction can be found between the tertiary hydrogen atom of TY5 and $\mathrm{Au}$ atom, the $\mathrm{Au}-\mathrm{H}$ distances are 2.64 and $2.53 \AA$, respectively (Fig. 5). The two hydrogen bonds between $\mathrm{O}$ atom of the methoxy group and two hydrogen atoms on ferrocene may contribute to the axial enantioselectivity of the reaction. In TS-A, $\pi-\pi$ stacking effect was found between two naphthyl groups from TY5 and laa parts respectively, while there is no such effect in TS-en-A. This may be the cause of high facial enantioselectivity of the reaction.

In summary, we developed an efficient gold(I)/TY-Phoscatalyzed intramolecular hydroarylation of ortho-alkynylaryl ferrocenes derivatives, which represents the highly enantioselective and diastereoselective simultaneous construction of axial and planar chiral $(S a, S p)$-naphthalene-fused ferrocene derivatives. The axial biaryl compound could be also delivered efficiently under the same reaction conditions. The here identified cationic $\mathrm{Au}$ (TY-Phos) ${ }^{+}$is responsible for the high yield and diastereoselectivity, good to excellent enantioselectivities. The DFT calculations explained the chirality-induction model and accounts for the high enantioselectivity. We believe that this well-designed, easily available gold catalyst $\mathrm{Au}$ (TY-Phos)Cl can be applied in other catalytic asymmetric transformations.

\section{Methods}

Typical procedure for simultaneous construction of axial and planar chirality by Gold/TY-Phos-catalyzed asymmetric hydroarylation. In a dried Schlenk tube, after the solution of $(S c, R s)-\mathrm{Au}(\mathrm{TY} 5) \mathrm{Cl}(5 \mathrm{~mol} \%, 8.2 \mathrm{mg})$ and $\mathrm{NaBAr}^{\mathrm{F}}(6 \mathrm{~mol} \%$, $10.6 \mathrm{mg}$, cas: $79060-88-1$, Energy Chemical, white powder) in DCM $(0.5 \mathrm{~mL})$ was stirred at room temperature for $15 \mathrm{~min}$. Then the above catalyst solution was added to the solution of $\mathbf{1}, \mathbf{4 - 5}(0.2 \mathrm{mmol})$ in DCM $(1.5 \mathrm{~mL})$ at $0{ }^{\circ} \mathrm{C}$. The reaction was determined by TLC analysis, after the 1, 4-5 was consumed completely. Solvent was removed in a rotary evaporator, purified by flash column chromatography on silica 
gel (Hexane/DCM $=10: 1$ to $5: 1)$ to afford the desired product 2, 6, 7. All new compounds were fully characterized (see the Supplementary Information).

\section{Data availability}

The data that support the findings of this study are available within the article, its Supplementary Information files and Supplementary Data files. All data underlying the findings of this work are available from the corresponding author upon reasonable request. The X-ray crystallographic coordinates for structures reported in this study have been deposited at the Cambridge Crystallographic Data Center (CCDC), under deposition numbers $2052064((S a, S p)-2 b b)$ and $2052077(((S c, R s)-\mathrm{TY} 6) \mathrm{AuCl})$. The data can be obtained free of charge from The Cambridge Crystallographic Data Center via http://www.ccdc.cam.ac.uk/ data_request/cif.

Received: 26 January 2021; Accepted: 30 June 2021; Published online: 29 July 2021

\section{References}

1. Zhang, J., Simon, M., Golz, C. \& Alcarazo, M. Gold-catalyzed atroposelective synthesis of 1,í-binaphthalene-2,3-diols. Angew. Chem. Int. Ed. 59, 5647-5650 (2020).

2. Takano, H., Shiozawa, N., Imai, Y., Kanyiva, K. S. \& Shibata, T. Catalytic enantioselective synthesis of axially chiral polycyclic aromatic hydrocarbons (PAHs) via regioselective $\mathrm{C}-\mathrm{C}$ bond activation of biphenylenes. J. Am. Chem. Soc. 142, 4714-4722 (2020)

3. Gicquiaud, J. et al. Brønsted acid-catalyzed enantioselective cycloisomerization of arylalkynes. Chem. Eur. J. 26, 16266-16271 (2020).

4. Peng, L. et al. Organocatalytic asymmetric annulation of ortho-alkynylanilines: synthesis of axially chiral naphthyl-C2-indoles. Angew. Chem. Int. Ed. 58, 17199-17204 (2019)

5. Arae, S. et al. Asymmetric synthesis of axially chiral benzocarbazole derivatives based on catalytic enantioselective hydroarylation of alkynes. Org. Lett. 20, 4796-4800 (2018).

6. Satho, M., Shibata, Y., Kimura, Y. \& Tanaka, K. Atroposelective synthesis of axially chiral all-benzenoid biaryls by the gold-catalyzed intramolecular hydroarylation of alkynones. Eur. J. Org. Chem. 26, 4465-4469 (2016).

7. Lotter, D., Neuburger, M., Rickhaus, M., Häussinger, D. \& Sparr, C. Stereoselective arene-forming aldol condensation: synthesis of configurationally stable oligo-1,2-naphthylenes. Angew. Chem. Int. Ed. 55, 2920-2923 (2016)

8. Fäseke, V. C. \& Sparr, C. Stereoselective arene-forming aldol condensation: synthesis of axially chiral aromatic amides. C. Angew. Chem. Int. Ed. 55, 7261-7264 (2016).

9. Link, A. \& Sparr, C. Organocatalytic atroposelective aldol condensation: synthesis of axially chiral biaryls by arene formation. Angew. Chem. Int. Ed. 53, 5458-5461 (2014).

10. Kadoya, N., Murai, M., Ishiguro, M., Uenishi, J. \& Uemura, M. Palladium(II)catalyzed asymmetric cycloisomerization of enynes for axially chiral biaryl construction. Tetrahedron Lett. 54, 512-514 (2013).

11. Urbano, A., Hernández-Torres, G., del Hoyo, A. M., Martínez-Carrióna, A. \& Carreño, M. C. Mild access to planar-chiral ortho-condensed aromatic ferrocenes via gold(I)-catalyzed cycloisomerization of ortho-alkynylaryl ferrocenes. Chem. Commun. 52, 6419-6422 (2016).

12. Shibata, T., Uno, N., Sasaki, T. \& Kanyiva, K. S. Pt-catalyzed enantioselective cycloisomerization for the synthesis of planar-chiral ferrocene derivatives. $J$. Org. Chem. 81, 6266-6272 (2016).

13. Ito, M., Okamura, M., Kanyiva, K. S. \& Shibata, T. Catalytic enantioselective synthesis of azepine-fused planar-chiral ferrocenes by Pt-catalyzed cycloisomerization. Organometallics 38, 4029-4035 (2019).

14. Hartung, T., Machleid, R., Simon, M., Golz, C. \& Alcarazo, M. Enantioselective Synthesis of 1,12-Disubstituted [4]Helicenes. Angew. Chem. Int. Ed. 59, 5660-5664 (2020). The catalytic asymmetric intramolecular cyclization for the stereoselective helical-arene formation, see.

15. Kinoshita, S. et al. Rhodium-catalyzed highly diastereo- and enantioselective synthesis of a configurationally stable s-shaped double helicene-like molecule. Angew. Chem. Int. Ed. 59, 11020-11027 (2020).

16. Nicholls, L. D. M. et al. TADDOL-derived cationic phosphonites: toward an effective enantioselective synthesis of [6] helicenes via Au-catalyzed alkyne hydroarylation. ACS Catal. 8, 6079-6085 (2018).

17. Yamano, R., Shibata, Y. \& Tanaka, K. Synthesis of single and double dibenzohelicenes by rhodium-catalyzed intramolecular $[2+2+2]$ and $[2+1+2$ $+1]$ cycloaddition. Chem. Eur. J. 24, 6364-6370 (2018).

18. González-Fernández, E. et al. Enantioselective synthesis of [6]carbohelicenes. J. Am. Chem. Soc. 139, 1428-1431 (2017).
19. Sanchez, I. G. et al. Oxahelicene NHC ligands in the asymmetric synthesis of nonracemic helicenes. Chem. Commun. 53, 4370-4373 (2017).

20. Jančařík, A. et al. Rapid access to dibenzohelicenes and their functionalized derivatives. Angew. Chem. Int. Ed. 52, 9970 (2013).

21. Metrano, A. J. \& Miller, S. J. Peptide-based catalysts reach the outer sphere through remote desymmetrization and atroposelectivity. Acc. Chem. Res. $\mathbf{5 2}$ 199-215 (2019).

22. Wang, Y.-B. \& Tan, B. Construction of axially chiral compounds via asymmetric organocatalysis. Acc. Chem. Res. 51, 534-547 (2018).

23. Zilate, B., Castrogiovanni, A. \& Sparr, C. Catalyst-controlled stereoselective synthesis of atropisomers. ACS Catal. 8, 2981-2988 (2018).

24. Link, A. \& Sparr, C. Stereoselective arene formation. Chem. Soc. Rev. 47, 3804-3815 (2018).

25. Loxq, P., Manoury, E., Poli, R., Deydier, E. \& Labande, A. Synthesis of axially chiral biaryl compounds by asymmetric catalytic reactions with transition metals. Coord. Chem. Rev. 308, 131-190 (2016).

26. Liu, C.-X., Gu, Q. \& You, S.-L. Asymmetric C-H bond functionalization of ferrocenes: new opportunities and challenges. Trends Chem. 2, 737-749 (2020).

27. Gao, D.-W., Gu, Q., Zheng, C. \& You, S.-L. Synthesis of planar chiral ferrocenes via transition-metal-catalyzed direct $\mathrm{C}-\mathrm{H}$ bond functionalization. Acc. Chem. Res. 50, 351-365 (2017).

28. Arae, S. \& Ogasawara, M. Catalytic asymmetric synthesis of planar-chiral transition-metal complexes. Tetrahedron Lett. 56, 1751-1761 (2015).

29. Dhbaibi, K., Favereau, L. \& Crassous, J. Enantioenriched Helicenes and Helicenoids Containing Main-Group Elements (B, Si, N, P). Chem. Rev. 119, 8846-8953 (2019).

30. Li, C., Yang, Y. \& Miao, Q. Recent progress in chemistry of multiple helicenes. Chem. Asian J. 13, 884-894 (2018).

31. Lina, W.-B., Lia, M., Fanga, L. \& Chen, C.-F. Recent progress on multidimensional construction of helicenes. Chin. Chem. Lett. 29, 40-46 (2018).

32. Shen, Y. \& Chen, C.-F. Helicenes: synthesis and applications. Chem. Rev. 112 1463-1535 (2012).

33. Wang, Y. et al. Gold-catalyzed asymmetric intramolecular cyclization of Nallenamides for the synthesis of chiral tetrahydrocarbolines. Angew. Chem. Int. Ed. 56, 15905-15909 (2017).

34. Chen, M. et al. Polymer-bound chiral gold-based complexes as efficient heterogeneous catalysts for enantioselectivity tunable cycloaddition. ACS Catal. 5, 7488-7492 (2015).

35. Zhang, Z.-M. et al. A new type of chiral sulfinamide monophosphine ligands: stereodivergent synthesis and application in enantioselective gold(I)-catalyzed cycloaddition reactions. Angew. Chem. Int. Ed. 53, 4350-4354 (2014).

36. Mato, M., Franchino, A., Garcia-Morales, C. \& Echavarren, A. M. Goldcatalyzed synthesis of small rings. Chem. Rev. https://doi.org/10.1021/acs. chemrev.0c00697 (2020). Recent reviews on asymmetric gold catalysis.

37. Hendrich, C. M., Sekine, K., Koshikawa, T., Tanaka, K. \& Hashmi, A. S. K. Homogeneous and Heterogeneous Gold Catalysis for Materials Science. Chem. Rev. https://doi.org/10.1021/acs.chemrev.0c00824 (2020).

38. Li, Y., Li, W. \& Zhang, J. Gold-catalyzed enantioselective annulations. Chem Eur. J. 23, 467-512 (2017).

39. Christian, A. H., Niemeyer, Z. L., Sigman, M. S. \& Toste, F. D. Uncovering subtle ligand effects of phosphines using gold(I) catalysis. ACS Catal. 7 , 3973-3978 (2017).

40. Zia, W. \& Toste, F. D. Recent advances in enantioselective gold catalysis. Chem. Soc. Rev. 45, 4567-4589 (2016).

41. Dorel, R. \& Echavarren, A. M. Gold(I)-catalyzed activation of alkynes for the construction of molecular complexity. Chem. Rev. 115, 9028-9072 (2015).

42. Qian, D. \& Zhang, J. Gold-catalyzed cyclopropanation reactions using a carbenoid precursor toolbox. Chem. Soc. Rev. 44, 677-698 (2015).

43. Zhang, P.-C., Wang, Y., Qian, D., Li, W. \& Zhang, J. Synthesis of 1 via the Sonogashira coupling reaction of $o$-ferrocenyl-bromo(iodo)benzene with 1ethynyl-2-alkoxynaphthalene. Chin. J. Chem. 35, 849 (2017).

44. $\mathrm{Mu}, \mathrm{D}$. et al. Streamlined construction of silicon-stereogenic silanes by tandem enantioselective C-H silylation/alkene hydrosilylation. J. Am. Chem. Soc. 142, 13459-13468 (2020).

45. $\mathrm{Hu}, \mathrm{Y}$. et al. Organocatalytic asymmetric $\mathrm{C}\left(\mathrm{sp}^{2}\right)-\mathrm{H}$ allylic alkylation: enantioselective synthesis of tetrasubstituted allenoates. Angew. Chem. Int. Ed. 59, 19820-19824 (2020)

46. Gu, X.-W. et al. Stereospecific Si-C coupling and remote control of axial chirality by enantioselective palladium-catalyzed hydrosilylation of maleimides. Nat. Commun. 11, 2904 (2020)

47. Liu, P. et al. Simultaneous control of central and helical chiralities: expedient helicoselective synthesis of dioxa[6]helicenes. J. Am. Chem. Soc. 142, 16199-16204 (2020)

48. Ma, C. et al. Atroposelective access to oxindole-based axially chiral styrenes via the strategy of catalytic kinetic resolution. J. Am. Chem. Soc. 142, 15686-15696 (2020). 
49. Romero-Arenas, A. et al. Ir-Catalyzed atroposelective desymmetrization of heterobiaryls: hydroarylation of vinyl ethers and bicycloalkenes. J. Am. Chem. Soc. 142, 2628-2639 (2020).

50. Lu, S. et al. Diastereo- and atroposelective synthesis of bridged biaryls bearing an eight-membered lactone through an organocatalytic cascade. J. Am. Chem. Soc. 141, 17062-17067 (2019).

51. Urbano, A., del Hoyo, A. M., Martínez-Carrión, A. \& Carreño, M. C. Asymmetric synthesis and chiroptical properties of enantiopure helical ferrocenes. Org. Lett. 21, 4623-4627 (2019).

52. Kamikawa, K. et al. Simultaneous induction of axial and planar chirality in arene-chromium complexes by molybdenum-catalyzed enantioselective ringclosing metathesis. Chem. Eur. J. 21, 4954-4957 (2015). Only one example of axial and planar chiral arene chromium complexes via asymmetric catalysis.

53. Li, H., Jia, P., Qian, N., Li, S. \& Jiao, P. Simultaneous construction of planar and central chiralities as well as unprecedented axial chirality on and around a ferrocene backbone. J. Org. Chem. 84, 2817-2828 (2019). Axial and planar chiral ferrocene derivatives via multi-step synthesis using chiral substrate.

54. Wang, H. et al. Pd-catalyzed enantioselective syntheses of trisubstituted allenes via coupling of propargylic benzoates with organoboronic acids. J. Am. Chem. Soc. 142, 9763-9771 (2020). For Ming-Phos ligands.

55. $\mathrm{Xu}, \mathrm{B}$. et al. Copper(I)/Ming-Phos-catalyzed asymmetric intermolecular [3+2] cycloaddition of azomethine Ylides with $\alpha$-Trifluoromethyl $\alpha, \beta$-unsaturated esters. ACS Catal. 7, 210-214 (2017).

56. Zhang, Z.-M., Xu, B., Xu, S., Wu, H.-H. \& Zhang, J. Diastereo- and enantioselective copper(I)-catalyzed intermolecular [3+2] cycloaddition of azomethine ylides with $\beta$-trifluoromethyl $\beta$, $\beta$-disubstituted enones. Angew. Chem. Int. Ed. 55, 6324-6328 (2016).

57. Zhou, L. et al. Enantioselective difunctionalization of alkenes by a palladiumcatalyzed heck/sonogashira sequence. Angew. Chem. Int. Ed. 59, 2769-2775 (2020). For Xu-Phos ligands.

58. Zhu, C., Chu, H., Li, G., Ma, S. \& Zhang, J. Pd-catalyzed enantioselective heck reaction of Aryl triflates and alkynes. J. Am. Chem. Soc. 141, 19246-19251 (2019).

59. Zhang, Z.-M. et al. Enantioselective dicarbofunctionalization of unactivated alkenes by palladium-catalyzed tandem heck/suzuki coupling reaction. Angew. Chem. Int. Ed. 58, 14653-14659 (2019).

60. Zhang, Z.-M. et al. Palladium/XuPhos-catalyzed enantioselective carboiodination of olefin-tethered aryl iodides. J. Am. Chem. Soc. 141, 8110-8115 (2019).

61. Zhang, Z.-M. et al. Palladium-catalyzed enantioselective reductive heck reactions: convenient access to 3,3-disubstituted 2,3-dihydrobenzofuran. Angew. Chem. Int. Ed. 57, 10373-10377 (2018).

62. Wang, L. et al. Enantioselective synthesis of isoxazolines enabled by palladium-catalyzed carboetherification of alkenyl oximes. Angew. Chem. Int. Ed. 59, 4421-4427 (2020).

63. Tao, M. et al. Pd/Xiang-Phos-catalyzed enantioselective intermolecular carboheterofunctionalization under mild conditions. Chem. Sci. 11, 6283-6288 (2020)

64. Zhang, P.-C., Wang, Y., Zhang, Z.-M. \& Zhang, J. Gold(I)/Xiang-Phoscatalyzed asymmetric intramolecular cyclopropanation of indenes and trisubstituted alkenes. Org. Lett. 20, 7049-7052 (2018).

65. $\mathrm{Hu}, \mathrm{H}$. et al. Enantioselective gold-catalyzed intermolecular $[2+2]-$ cycloadditions of 3-styrylindoles with N-allenyl oxazolidinone. Org. Chem. Front. 3, 759-763 (2016).

66. Chu, H., Cheng, J., Yang, J., Guo, Y.-L. \& Zhang, J. Asymmetric dearomatization of indole by palladium/PC-Phos-catalyzed dynamic kinetic transformation. Angew. Chem. Int. Ed. 59, 21991-21996 (2020).

67. Zhang, P.-C., Han, J. \& Zhang, J. Pd/PC-Phos-catalyzed enantioselective intermolecular denitrogenative cyclization of benzotriazoles with allenes and N-allenamides. Angew. Chem. Int. Ed. 58, 11444-11448 (2019).

68. Wang, L., Chen, M., Zhang, P., Li, W. \& Zhang, J. Palladium/PC-Phoscatalyzed enantioselective arylation of general sulfenate anions: scope and synthetic applications. J. Am. Chem. Soc. 140, 3467-3473 (2018).

69. Lin, T.-Y. et al. Design and synthesis of TY-Phos and application in palladium-catalyzed enantioselective fluoroarylation of gem-difluoroalkenes Angew. Chem. Int. Ed. 59, 22957-22962 (2020).

70. Jia, M. \& Bandini, M. Counterion effects in homogeneous gold catalysis. ACS Catal. 5, 1638-1652 (2015). Coordinating ability of different counterions associated with active gold catalysts can also significantly modulate their electrophilic nature.

71. Chen, Y., Yekta, S. \& Yudin, A. K. Modified BINOL ligands in asymmetric catalysis. Chem. Rev. 103, 3155-3212 (2003). The potential applications of the axial and planar chiral naphthol $\mathbf{3}$ is interest in asymmetric catalysis and material sciences, see.
72. Li, Y., Manickam, G., Ghoshal, A. \& Subramaniam, P. More efficient palladium catalyst for hydrogenolysis of benzyl groups. Synth. Commun. 36 925-928 (2006)

73. Zhao, Y. \& Truhlar, D. G. The M06 suite of density functionals for main group thermochemistry, thermochemical kinetics, noncovalent interactions, excited states, and transition elements: two new functionals and systematic testing of four M06-class functionals and 12 other functionals. Theor. Chem. Acc. 120, 215-241 (2008).

74. Frisch, M. J. et al. Gaussian 09, Revision D.01; (Gaussian, Inc., 2009).

75. Dunning Jr, T. H. \& Hay, P. J. In Modern Theoretical Chemistry, H. F. Schaefer III 3rd edn, 1-28 (Plenum, 1977).

76. Fuentealba, P., Preuss, H., Stoll, H. \& Szentpály, L. V. A proper account of core-polarization with pseudopotentials: single valence-electron alkali compounds. Chem. Phys. Lett. 89, 418-422 (1982).

77. Marenich, A. V., Cramer, C. J. \& Truhlar, D. G. Universal solvation model based on solute electron density and on a continuum model of the solvent defined by the bulk dielectric constant and atomic surface tensions. J. Phys. Chem. B 113, 6378-6396 (2009).

78. Truhlar, D. G. \& Gordon, M. S. From force fields to dynamics: classical and quantal paths. Science 249, 491-498 (1990).

79. Gonzalez, C. \& Schlegel, H. B. An improved algorithm for reaction path following. J. Chem. Phys. 90, 2154-2161 (1989).

\section{Acknowledgements}

We gratefully acknowledge the funding support of NSFC (22031004, 21921003), Shanghai Municipal Education Commission (20212308), and the postdoctoral research fund CPSF (2019M661420). We greatly appreciate Ph.D. Yanfei Niu at East China Normal University for her kind help with X-ray single crystal structural analyses, M.S. Lian-Fang Yang at East China Normal University for her kind help with NMR structural analyses.

\section{Author contributions}

J.Z., P.-C.Z., and H.-H.W., conceived the project, analyzed the data and wrote the paper P.-C.Z., performed the most of experiments. Y.-L.L. and J.H. helped in synthesis of substrates 1. Z.L. did the DFT calculations. All authors discussed the results and commented on the paper.

\section{Competing interests}

The authors declare no competing interests.

\section{Additional information}

Supplementary information The online version contains supplementary material available at https://doi.org/10.1038/s41467-021-24678-5.

Correspondence and requests for materials should be addressed to H.-H.W., Z.L. or J.Z.

Peer review information Nature Communications thanks Peng Jiao and the other anonymous reviewer(s) for their contribution to the peer review of this work. Peer reviewer reports are available.

Reprints and permission information is available at http://www.nature.com/reprints

Publisher's note Springer Nature remains neutral with regard to jurisdictional claims in published maps and institutional affiliations.

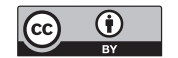

Open Access This article is licensed under a Creative Commons Attribution 4.0 International License, which permits use, sharing, adaptation, distribution and reproduction in any medium or format, as long as you give appropriate credit to the original author(s) and the source, provide a link to the Creative Commons license, and indicate if changes were made. The images or other third party material in this article are included in the article's Creative Commons license, unless indicated otherwise in a credit line to the material. If material is not included in the article's Creative Commons license and your intended use is not permitted by statutory regulation or exceeds the permitted use, you will need to obtain permission directly from the copyright holder. To view a copy of this license, visit http://creativecommons.org/ licenses/by/4.0/.

(C) The Author(s) 2021 